\title{
Pyrosol Generation of $\mathrm{ZnO}$ Nanoparticles and Structured Thin Films
}

\author{
Denis Sweatman*, Chutima Eamchotchawalit ${ }^{\dagger}$, Joydeep Dutta \\ *Griffith School of Engineering, Griffith University, Queensland, Australia. \\ Email: d.sweatman@griffith.edu.au \\ ${ }^{\dagger}$ Thailand Institute of Scientific and Technological Research (TISTR), Bangkok, Thailand. \\ Email: chutima@tistr.or.th \\ ${ }^{\ddagger}$ School of Engineering and Technology, Asian Institute of Technology, Pathumthani, Thailand. \\ Email: joy@ait.ac.th
}

\begin{abstract}
Zinc oxide is a material of considerable research interest because of its properties eg photocatalysis, piezoelectricity. This paper describes the production of zinc oxide thin films, nanoparticles and combinations by the ultrasonic pyrosol process using a dual heater configuration.
\end{abstract}

Keywords; pyrosol; nanoparticle; zinc oxide; thin film.

\section{INTRODUCTION}

The characteristics of zinc oxide have lead to considerable research being undertaken into this material. Its piezoelectric, optoelectronic and photocatalytic properties mean that many researchers are actively investigating this material.

For the application of photocatalysis, a large active surface is required. Normal pyrolysis methods of dissociating precursors onto a hot substrate [1] can produce films with only a limited surface area. Deposition of nanoparticles from solution can increase the surface area. Production of nanoparticles however can also be made via the inexpensive ultrasonic spray pyrolysis (pyrosol) process when droplets pass through a heated zone before impinging on the substrate [2]. The size of the particle depends on the droplet size, concentration of precursor and temperatures used. In this paper, zinc oxide films of varying characteristics are produced by the pyrosol process with combinations of heat zone temperatures.

\section{EXPERIMENTAL}

Pyrosol deposition was performed using zinc acetate dihydrate (Merck) solution at concentrations below $0.1 \mathrm{M}$ in water. Substrates used were microscope slides ultrasonically cleaned in detergent solution and/or cleaned with an abrasive plastic pad before rinsing in water, DI water and air-blast dried.

The ultrasonic pyrosol system consisted of a $\sim 1 \mathrm{MHz}$ generator (TISTR) coupled through a stabilizing water jacket to a plastic container holding the sample liquid as illustrated in Figure 1. Approximately $30 \mathrm{ml}$ of solution was placed in the container and the ultrasonically generated aerosol was transferred through a $\sim 25 \mathrm{~mm}$ diameter stainless steel tube by means of very low pressure compressed air at a flow rate of less than $1 \mathrm{~L} / \mathrm{min}$. The emerging vapour was directed either toward a heated glass substrate placed on a hotplate or to a $100 \mathrm{ml}$ beaker filled with deionised water. A second hotplate was placed below and coupled to the stainless steel tube near the sample substrate and was able to be heated to $\sim 400^{\circ} \mathrm{C}$ to either preheat the emerging droplets or to evaporate the water solvent so that hot solid particles emerged from the tube. Temperatures were measured by K-type thermocouples. SEM images were obtained on either a JEOL FESEM JSM6340F (TISTR) or JEOL JSM6301F (MTEC).

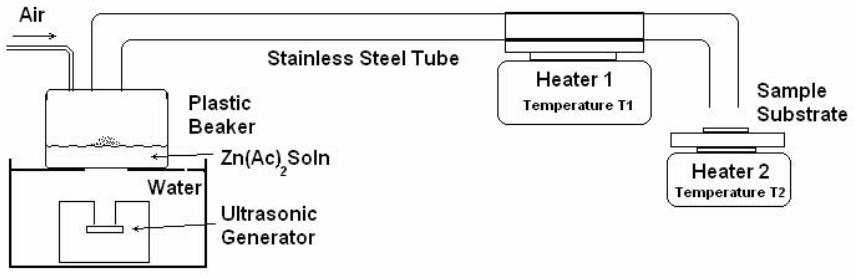

Figure 1. Pyrosol deposition system using two heaters.

\section{RESULTS AND DISCUSSION}

When the temperature of the tube heater (1) was at room temperature with substrate heater (2) hot $\left(\sim 400^{\circ} \mathrm{C}\right)$, decomposition occurred on the substrate and Figure 2 shows the SEM image of the film formed for T2 $=400 \pm 20^{\circ} \mathrm{C}$.

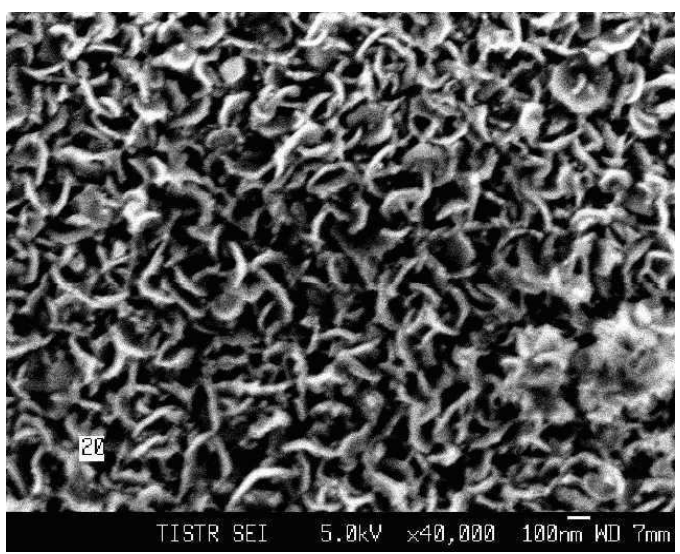

Figure 2. SEM image of T1 low, T2 high film 
In 30 minutes of deposition a film of $\sim 750 \mathrm{~nm}$, as measured by a Dektak profilometer, was formed from a starting solution of $0.1 \mathrm{M} \mathrm{Zn}(\mathrm{Ac})_{2}$. The perpendicular to substrate growth of "cauliflower" like structures [3] shows the growth characteristics of $\mathrm{ZnO}$ which is know to have many orientations [4] especially when deposited from an aqueous environment.

For tube heater (1) at $\sim 400^{\circ} \mathrm{C}$, the zinc acetate solution was decomposed and solvent vapourised during transit through the tube emerging as a solid particle of $\mathrm{ZnO}$. A beaker of water was used to capture the particles.

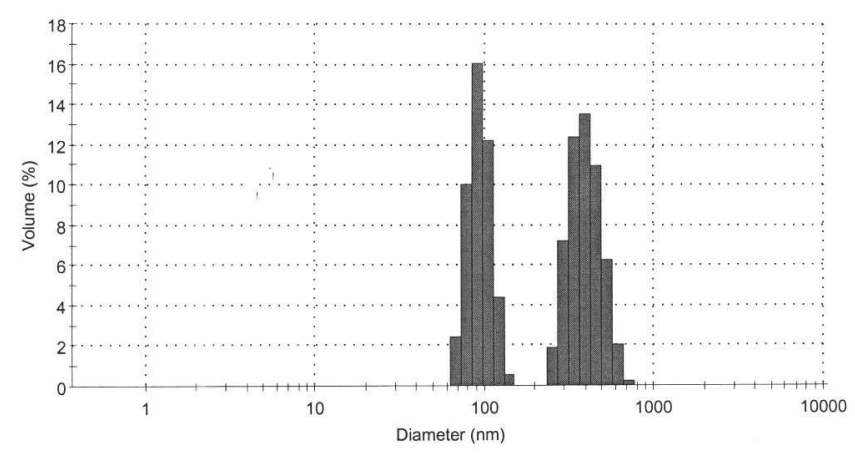

Figure 3. Particle sizing for $0.1 \mathrm{M} \mathrm{Zn}(\mathrm{Ac})_{2}$ sample

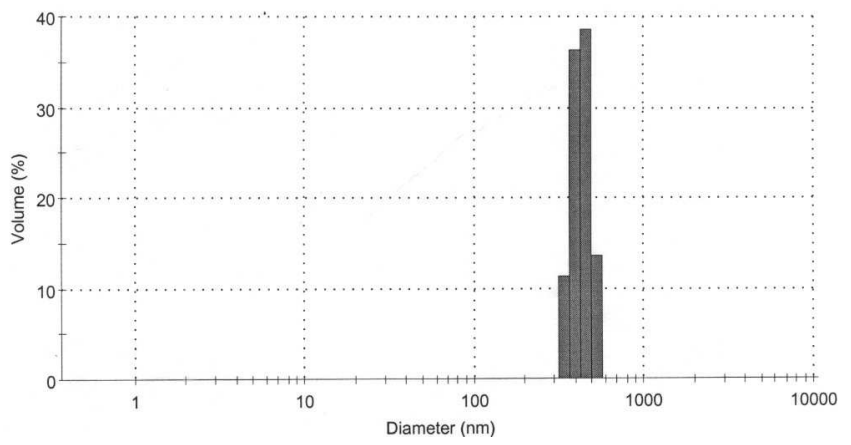

Figure 4. Particle sizing for $0.03 \mathrm{M} \mathrm{Zn}(\mathrm{Ac})_{2}$ sample

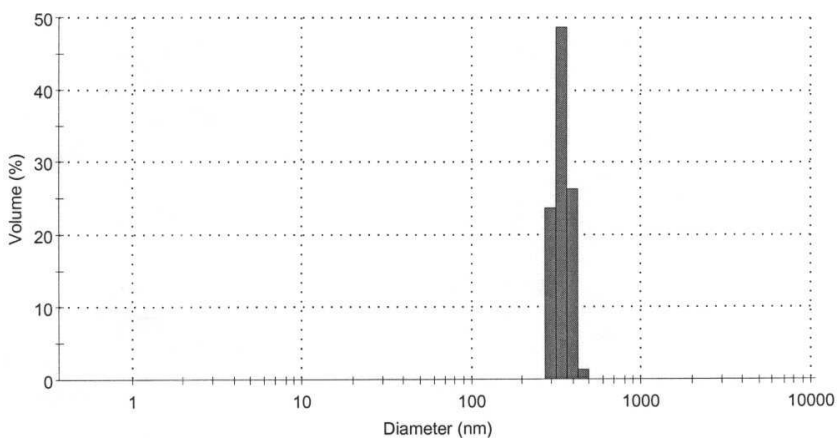

Figure 5. Particle sizing for $0.008 \mathrm{M} \mathrm{Zn}(\mathrm{Ac})_{2}$ sample

After filtering with filter paper (Whatman No.1 11micron) particle sizing by volume, using a Malvern Zetasizer NanoZS, measured particles of $80-120 \mathrm{~nm}$ and $300-600 \mathrm{~nm}$ for $0.1 \mathrm{M}$, $200-500 \mathrm{~nm}$ for $0.03 \mathrm{M}$ and $150-300 \mathrm{~nm}$ for $0.008 \mathrm{M}$ zinc acetate solutions. These values agree with calculations for an aerosol particle size of near 5 microns.

The temperature $\mathrm{T} 1$ for the $0.1 \mathrm{M} \mathrm{Zn}(\mathrm{Ac})_{2}$ sample shown in Figure 3 was noted to be below $350^{\circ} \mathrm{C}$ for a significant fraction of the collection time. This may explain the two particle distribution in Figure 3.

Figure 6 displays the SEM image of particles produced from a similar process with $0.1 \mathrm{M} \mathrm{Zn}(\mathrm{Ac})_{2}$ starting solution and tube heater (1) at $\sim 390^{\circ} \mathrm{C}$ while substrate heater (2) was at $140^{\circ} \mathrm{C}$. This image diplays a range of particle sizes from $0.5 \mu \mathrm{m}$ to $1.5 \mu \mathrm{m}$ diameter which may result again from slight variations in T1. Also apparent and shown more clearly in Figure 7 are the smaller subparticles of $\sim 30 \mathrm{~nm}$ diameter which agglomerate on the evaporation of the water to make the larger particle and the hollow nature of some particles leading to large surface area and porosity.

These subparticles appear to arise from the hydrolysis of the zinc acetate solution which is heated as it passes through the stainless steel tube. Control of the particle characteristics could be achieved by adjusting solution concentration, ultrasonic droplet size, tube temperature and residence time.

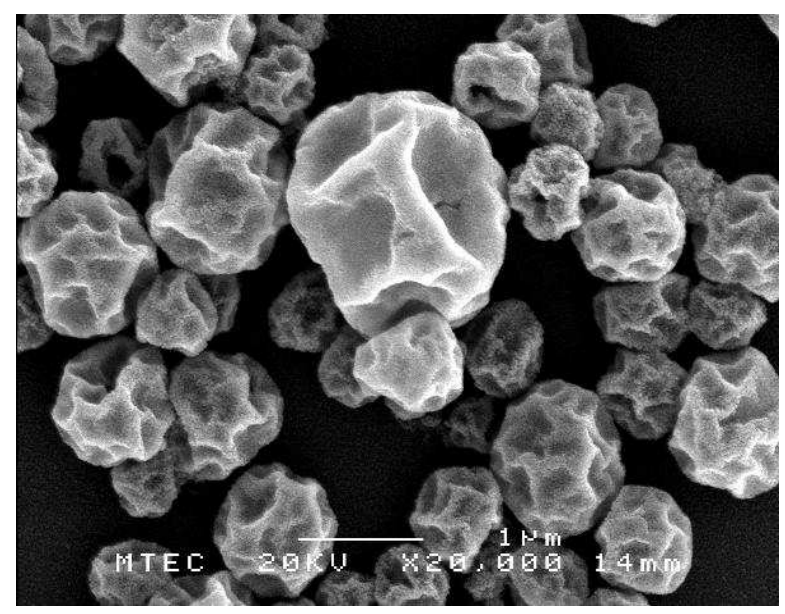

Figure 6. SEM image of T1 high, T2 low deposit

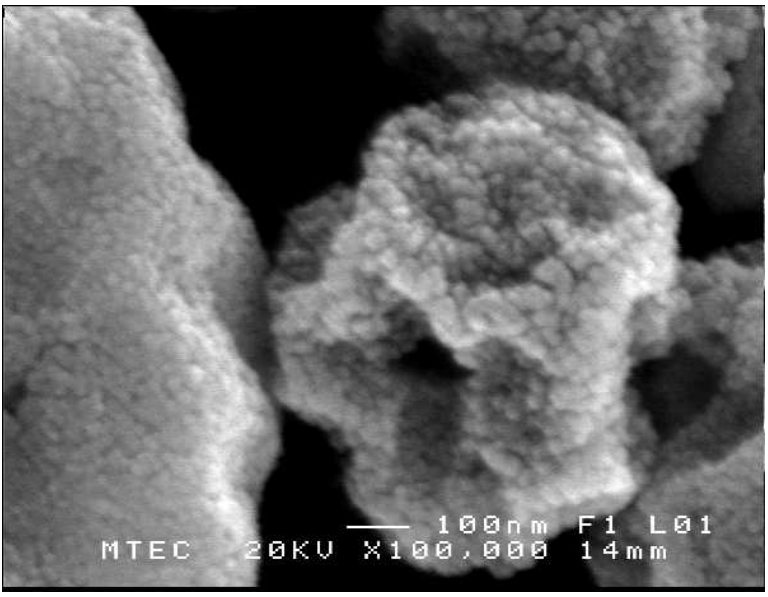

Figure 7. SEM showing agglomerated particles. 
Zinc Oxide nanorods can be formed when $\mathrm{T} 1$ is at an intermediate temperature ie. less than $300^{\circ} \mathrm{C}$ and $\mathrm{T} 2$ is high ie. above $320^{\circ} \mathrm{C}$ as shown in Figure 8. Here the SEM image displays nanorods again formed from an approximately $30 \mathrm{~nm}$ subparticle with $\sim 5$ particles per nanorod. These may result from the deposition of droplets containing small particles formed by hydrolysis during transit through the heater 1 region. Final evaporation of the water droplet on the substrate results in agglomeration of only a few subparticles into nanorods of $\sim 5$ particles.

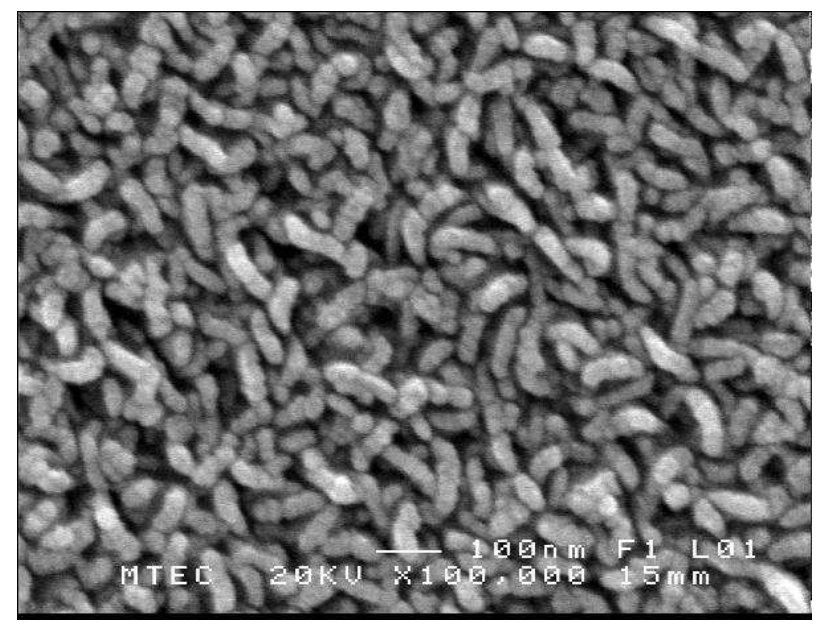

Figure 8. SEM image of T1 med, T2 high film.

Figure 9 shows the result of a multiple temperature regime where both $\mathrm{T} 1$ and $\mathrm{T} 2$ were adjusted to create particles (T1 high, T2 low) and nanorods (T1 intermediate, T2 high) on the same substrate.

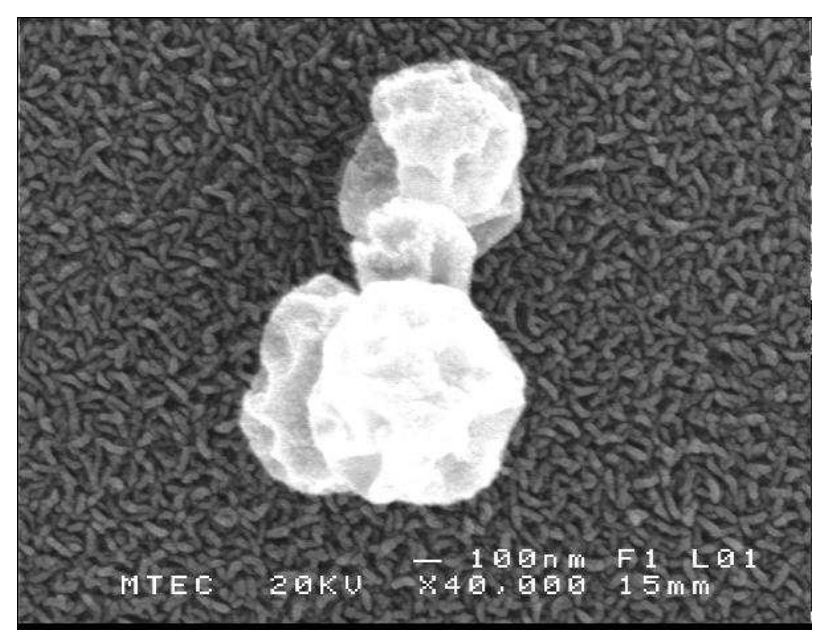

Figure 9. SEM image of T1,T2 sequenced deposit

XRD spectra (JEOL JDX-3530) of the crystal structure of the films restricted to the $(002)\left(2 \theta=34.4^{\circ}\right)$ and (101) $\left(2 \theta=36.2^{\circ}\right)$ regions are displayed in Figures 10 and 11. The peak positions correspond well to those expected for Zincite ( $\mathrm{ZnO}$ mineral from ICDD database) with variation observed in the ratio of the peak heights for T1 low, T2 high (cauliflower) and T1 med, T2 high (nanorod). This variation can result from orientation or dopant effects[5].

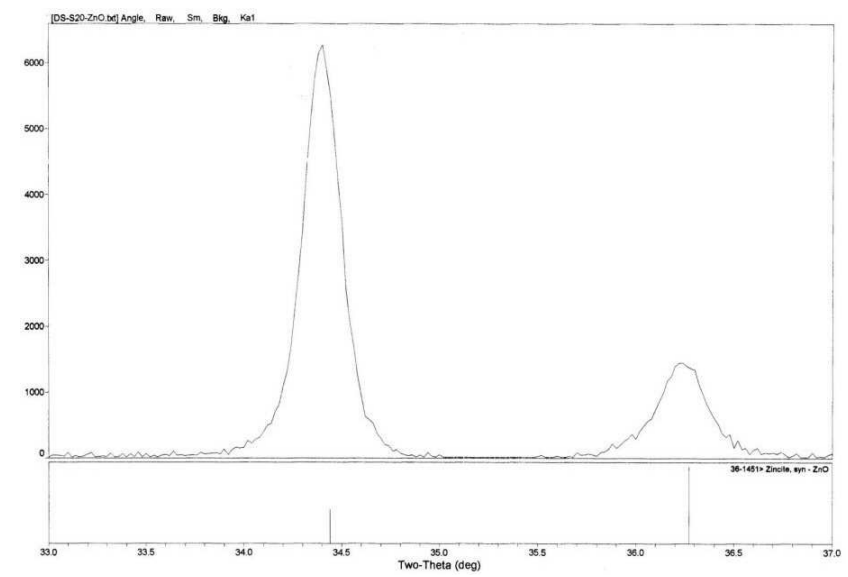

Figure 10. XRD spectra for T1 low, T2 high film

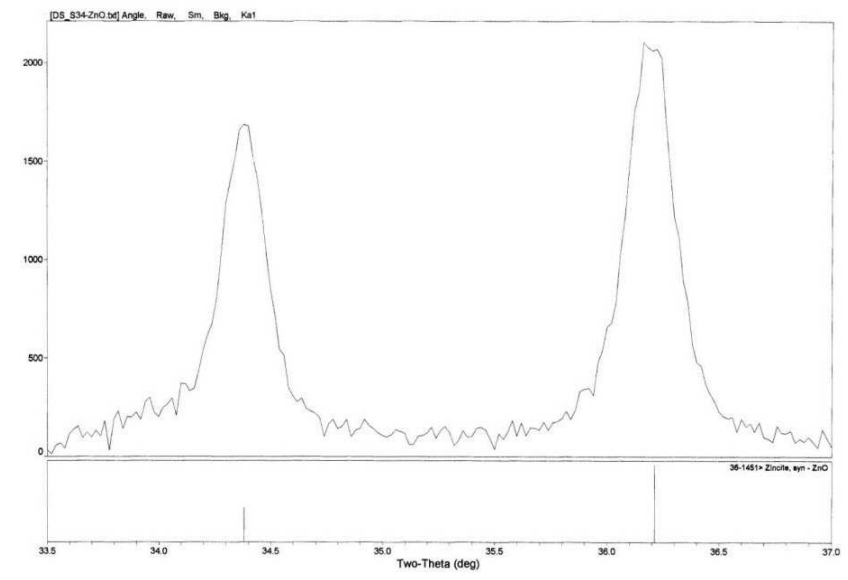

Figure 11. XRD spectra for T1 med, T2 high film

The width of the XRD peaks is an indicator of crystallite size or lattice strain and from the data, sizes of $33-43 \mathrm{~nm}$ for sample T1 low, T2 high and 35-45nm for sample T1 med, T2 high were determined. These correspond well to the size of features and subparticles observed in Figures 2 and 8.

\section{CONCLUSION}

The combination of two process temperatures enables films with differing properties to be deposited. By adjusting the time duration it should be possible to create a larger number of large particles $(\sim 1 \mu \mathrm{m})$ and subsequently deposit nanorods to coat these for enhanced surface area. This may also provide improved particle adhesion to the substrate. Provided the surfaces are active[4], which may be modified by using different solvents and carrier gases[5], the enhanced surface area from this process could increase photocatalytic activity. 


\section{ACKNOWLEDGMENTS}

The authors wish to thank the Thailand Institute of Scientific and Technological Research (TISTR) and the National Science and Technology Development Agency (NSTDA) of Thailand (MTEC, Nectec and Nanotec) for providing access to SEM, XRD, profilometer and particle sizing facilities and Punthinee, Ruh Ullah and Abhilash Sugunan for their help and expertise.

\section{REFERENCES}

[1] B.Joseph, P.K.Manoj and V.K.Vaidyan, "Studies on preparation and characterization of indium doped zinc oxide films by chemical spray deposition.", Bull. Mater. Sci., Vol 28, No. 5, 2005, pp487-493.

[2] W.H.Suh and K.S.Suslick, "Magnetic and Porous Nanospheres from Ultrasonic Spray Pyrolysis," J. Am. Chem. Soc, vol. 127, 2005, pp. 12007-12010

[3] J.Dutta, J.Perrin, T.Emeraud, J-M.Laurent, A.Smith,'Pyrosol deposition of flourine-doped tin dioxide thin films", Journal of Material Science, Vol 30, 1995, Clarendon, pp.53-62.

[4] D.Li and H.Haned,"Morphologies of zinc oxide particles and their effects on photocatalysis", Chemosphere, Vol 51, 2003, pp. 129-13.

[5] [1] J.Song, W-Y. Cho, K-S. Lim, K-H. Yoon, G-J. Yu, "Properties of ZnO:Al thin films for solar cells by pyrosol method", WCPEC, 1994, p631. 